\title{
Time of concentration of surface flow in complex hillslopes
}

\author{
Touraj Sabzevari $^{1^{*}}$, Bahram Saghafian ${ }^{2}$, Ali Talebi ${ }^{3}$, Reza Ardakanian ${ }^{4}$ \\ ${ }^{1}$ Department of Civil Engineering, Estahban Branch, Islamic Azad University, Estahban, Iran. \\ ${ }^{2}$ Science and Research Branch, Islamic Azad University, Tehran, Iran. \\ ${ }^{3}$ Faculty of Natural Resources, Yazd University, Yazd, Iran. \\ ${ }^{4}$ Department of Civil Engineering, Sharif University of Technology, Tehran, Iran. \\ *Corresponding author. Tel.: 00989177151596. Fax: 00987112360352.E-mail: T_sabzevari@iauestahban.ac.ir or tooraj419@yahoo.com
}

\begin{abstract}
Time of concentration (TC) of surface flow in watersheds depends on the coupled response of hillslopes and stream networks. The important point in this background is to study the effects of the geometry and the shape of complex hillslopes on the time of concentration considering the degree of flow convergence (convergent, parallel or divergent) as well as the profile curvature (concave, straight or convex). In this research, the shape factor of complex hillslopes as introduced by Agnese et al. (2007) is generalized and linked to the TC. A new model for calculating TC of complex hillslopes is presented, which depends on the plan shape, the type and degree of profile curvature, the Manning roughness coefficient, the flow regime, the length, the average slope, and the excess rainfall intensity. The presented model was compared to that proposed by Singh and Agiralioglu (1981a,b) and Agiralioglu (1985). Moreover, the results of laboratory experiments on the travel time of surface flow of complex hillslopes were used to calibrate the model. The results showed that TC for convergent hillslopes is nearly double those of parallel and divergent ones. TC in convex hillslopes was very close to that in straight and concave hillslopes. While the effect of convergence on TC is considerable, the curvature effect confirmed insignificant. Finally, in convergent hillslopes, TC increases with the degree of convergence, but in divergent hillslopes, it decreases as degree of divergence increases.
\end{abstract}

Keywords: Complex hillslopes; Time of concentration; Surface flow.

\section{INTRODUCTION}

Most rainfall-runoff models require some sort of a parameters describing the response time of watersheds. The most common response time parameters used in hydrologic models are time of concentration, lag time and time to equilibrium. For example, design of urban drainage systems using rational formula requires an estimate of the time of concentration to determine the critical rainfall intensity (Ben-Zvi, 1984). Snyder, Clark and SCS unit hydrograph methods require an estimate of the watershed response time. The Muskingum flood routing method also makes use of the travel time in river reaches. Meynink (1978) showed that varying the time of concentration from one half to twice the initial value respectively changed the peak discharge by 1.64 to 0.48 times that corresponding to the initial value for a typical $5 \mathrm{~km}^{2}$ watershed on the Darling Downs in Australia. Since the value of design flood is in reverse proportion to the response time, more efficient design relies on better estimate of the time of concentration.

Ben-Zvi (1984) defined the time of concentration as the time from the initiation of rainfall, to the time when the catchment discharge attains (nearly) 0.8 of the equilibrium discharge. Other researchers postulate that time of concentration is the same as the time to equilibrium for the kinematic condition when the rainfall duration is greater than the time of concentration (eg., Saghafian and Julien, 1995; Ben-Zvi, 1995). Beven (1982) defined the time of concentration as the time at which a steady-state flow profile is developed over the entire hillslope, assuming a constant input rate for a sufficient length of time.

Eagleson (1962); Meynink (1978); Overton and Meadows (1976); Kirpich (1940), McCuen et al., (1984); Akan (1986); Agiralioglu (1985-1988); Singh and Agiralioglu (1981a, 1981b, 1982); Henderson and Wooding (1964); Saghafian and Julien, (1995) among others, have presented TC relationships for simple hillslopes or complex watersheds. Most of these relationships are functions of plane length, average slope, Manning or Chezy coefficient, and in some cases, average excess rainfall intensity. However, the subject of plan shape and curvature of hillslopes or sub-catchments is not considered in their equations accurately. To compute TC of a convergent or divergent sub-catchment, most hydrologists proceed as if in the rectangular or parallel case not considering its perfect geometry, while in our research, the importance of this issue is investigated more precisely.

Morgali and Linsley (1965) studied TC for parallel hillslopes. However, the geometry of hillslopes, i.e. profile curvature (concave, straight or convex) as well as the hillslopes shape (convergent, divergent or parallel) may render direct effect on the TC. The profile curvature is related to the variations of the slope which in turn affects the velocity of water along the hillslope. Agiralioglu (1985) studied the lag time of convergent hillslopes while Agiralioglu and Singh (1981) presented equations to calculate the lag time and the time of concentration for divergent hillslopes.

The average slope of the watershed hillslopes is one of the parameters present in most TC equations. However, most researchers have assumed straight hillslopes by ignoring the effect of profile curvature. Recently, Troch et al., (2002, 2003); Hilberts et al., (2004, 2007) and Berne et al., (2005) have shown that subsurface flow processes are influenced by plane shape, profile curvature and the hydraulic properties of the porous medium. Furthermore, Talebi et al., (2008a) investigated stability of complex hillslopes due to subsurface flow. They used Evans (1980) equation for modelling three-dimensional shapes of nine complex hillslopes and introduced a width function for convergent and divergent hillslopes. They also studied the stability of the width functions in steady and unsteady conditions. Their results proved that the geometry of hillslopes has a direct effect on the stability of hillslopes. 
O'Loughlin (1981) showed that the size of hillslopes saturated zones depends strongly on the topographic convergence or divergence. Aryal et al. (2005) presented equations for computing the travel time of subsurface flows. They showed that the hillslope travel time in subsurface flow is dependent on hillslope length, hydraulic conductivity, convergence ratio, profile factor and recharge rate. Based on their results, the divergent hillslopes can exhibit travel times that are double those of the convergent hillslopes, and the concave slopes tend to have lower travel times than planar or convex slopes.

Sabzevari et al. (2010) and Sabzevari (2010) studied the rate of saturation of complex hillslopes based on the subsurface flow. They have also investigated the effects of saturation upon the travel times of complex hillslopes and proved that the rates of saturation in complex hillslopes are not the same. Based on their results, the convergent hillslopes become saturated very quickly and they showed longer saturation zone length with shorter travel time compared to the parallel and divergent slopes. The saturation capacity, and subsurface travel time of compound hillslopes depend on parameters such as soil depth, porosity, soil hydraulic conductivity, plane shape (convergent, parallel or divergent), hillslope length, profile curvature (concave, straight or convex) and recharge rate to the groundwater table. A new equation was presented for calculating subsurface travel time for all complex hillslopes. The role played by the geometry of hillslopes in subsurface flows seems to be of great importance, yet more work is needed in the case of surface flow.

Agnese et al. (2001) presented an analytical solution of the overland flow equations over a rectangular straight hillslope using the non-linear storage-based model first introduced in the hydrological literature by Horton (1938). This analytical solution was extended to convergent and divergent surfaces and to concave and convex profiles by Agnese et al. (2007). They approximated the conical convergent and divergent surfaces by a trapezoidal shape, and the overland flow was assumed to be always one-dimensional. They also introduced a shape factor, synthesizing the combined effect of both plan form geometry and profile shape on the hydrologic response at the hillslope scale.

In this study, the three dimensional (3D) shape factor of complex hillslopes introduced by Agnese et al. (2007) is generalized and a new equation for TC of all complex hillslopes is presented. This work is conducted based on the Evans (1980) comprehensive geometry model. This model has been verified by Troch et al., (2002, 2003); Hilberts et al., (2004, 2007); Berne et al., (2005) and Talebi et al., (2008a, b) in modelling of subsurface flow in complex hillslopes.

Though factors such as drainage surfaces of hillslopes, Manning coefficient, slope, and excess rainfall affect extremely on response time of hillslopes- and perhaps even more with respect to the geometry of complex hillslopes, the most important goal of this research is to study the effects of geometry of complex hillslopes on TC. Thus, the specific objectives of this research are 1) to present an analytical TC equation for complex hillslopes; and 2) to study the effect of the 3D shape of the hillslope (plane shape and profile curvature) on the TC.

\section{METHODOLOGY}

\section{Hillslope geometry}

To study the effect of hillslope topography on the time of concentration, the hillslopes are characterized by a combination of curvature in the gradient direction (profile curvature) and the direction perpendicular to the gradient (plan curvature). Then, three different profile curvatures (concave, straight and convex) and three different plane shapes (convergent, parallel and divergent) are identified.

The profile curvature is important because it affects the acceleration of mass flowing down the slope. The plane curvature defines topographic convergence which is an important control on the surface flow concentration (Troch et al., 2002).

The surface of an individual hillslope (Fig. 2) may be represented by the following function (Evans, 1980):

$$
z(x, y)=E+H(1-x / L)^{n}+\omega y^{2}
$$

where $z$ is the elevation, $x$ is the horizontal distance lengthwise measured in the downstream direction of the surface, $y$ is the horizontal distance from the slope centre in the direction perpendicular to the length direction (the width direction), $E$ is the minimum elevation of the surface above an arbitrary datum, $H$ is the maximum elevation difference on the surface, $L$ is the horizontal length of the surface, $n$ is the profile curvature parameter, and $\omega$ is the plan shape parameter.

We allow the profile curvature (defined by $n$ ) to assume values less than, equal to, or greater than unity and the plan curvature (defined by $\omega$ ) to assume either a positive, zero, or negative value. In order to reduce the number of free parameters that define the topographic surface of the hillslope, we take $\omega=+H / L^{2}$ for convergent hillslopes and $\omega=-H / L^{2}$ for divergent hillslopes (Talebi et al., 2008a, b). Fig. 1 illustrates nine basic hillslope types that are formed by combining three plan and three profile curvatures. Fig. 2 illustrates the threedimensional view of a convergent hillslope with a convex surface profile.

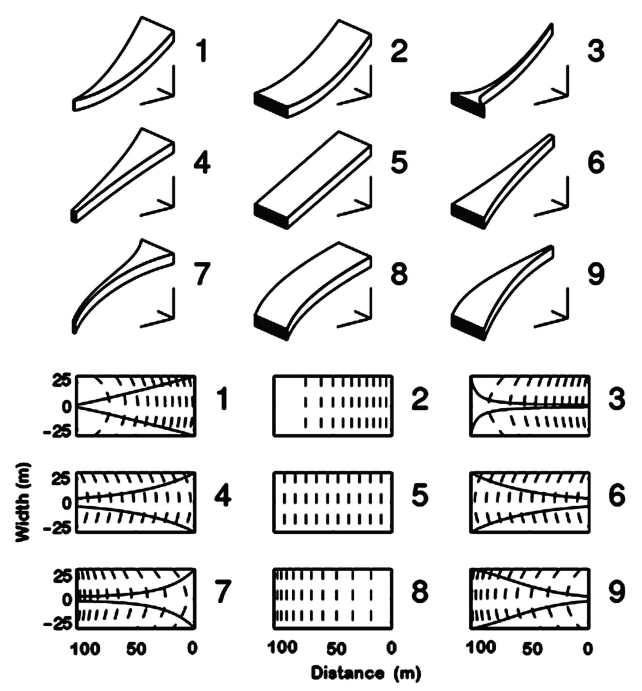

Fig. 1. 3D view (top) and 2D plan of the contour lines and slope divides (bottom) of the nine hillslopes considered in this study (after Hilberts et al., 2004).

The width of the hillslope measured in the $y$ direction is given by (Talebi et al., 2008a):

$$
w(x)=c_{w} \exp \left\{c_{s}\left(1-\frac{x}{L}\right)^{2-n}\right\}
$$

and 


$$
c_{s}=\frac{2 \omega L^{2}}{n(2-n) H}
$$

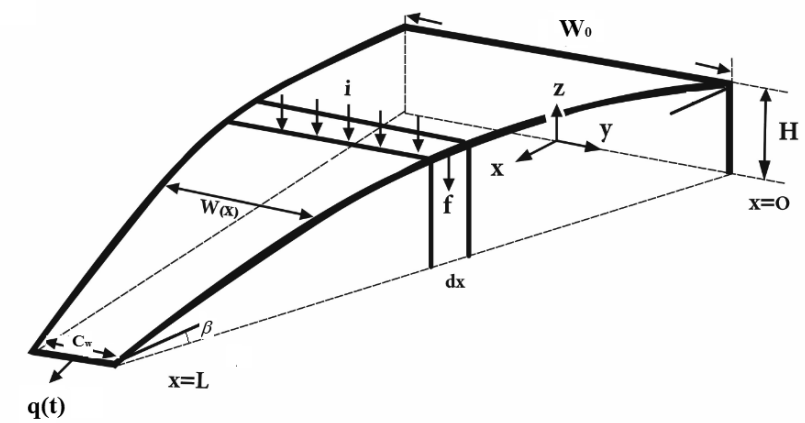

Fig. 2. Three-dimensional view of a convergent hillslope with a convex surface profile.

where $c_{w}$ defines the width of the hillslope at the outlet $(x=L)$ and $c_{s}$ defines the degree of topographic convergence. The hillslope drainage area $A$ at a distance $x$ is:

$$
A(x)=\int_{0}^{x} w(u) d u .
$$

\section{Surface flow model for complex hillslopes}

A stationary rainfall of intensity $(i)$, uniformly distributed over the area, is applied to the hillslope (Fig. 2). Soil characteristics are also spatially uniform. The runoff is generated through a fast mechanism, in which the water moves as a thin sheet above the soil surface (hillslope flow). The mass continuity equation applied to an infinitesimal element of the hillslope of length $d x$ may be expressed by (Agnese et al., 2001):

$\frac{\partial h_{x}(t)}{\partial t}+\frac{\partial Q_{x}(t)}{\partial x}=r$

in which $Q_{x}(t)$ is the discharge per unit width at time $t$ and distance $x$ measured from the top of the hillslope, $h_{x}(t)$ is the local depth of surface flow at distance $x$ and $r=i-f$ is the rainfall excess intensity where $i$ and $f$ are the rainfall intensity and the infiltration rate, respectively.

Agnese et al., (2007) solved Eq. (5) analytically for complex hillslopes $r-q_{0}>0$, as follows:

$$
\sum_{j=0}^{\infty} \frac{1}{1+m j}\left[\left(\frac{q}{r}\right)^{(1+m j) / m}-\left(\frac{q_{0}}{r}\right)^{(1+m j) / m}\right]=\phi_{s}^{-1} r^{(m-1) / m} k_{*}^{1 / m} t,
$$

where $m$ are parameters that are assumed to be constant ( $m$ is usually taken to be equal to $5 / 3$ for turbulent flow and to 3 for laminar flow), $k_{*}=S^{0.5} /\left(n_{h} L\right), S$ is the average slope $(=H / L), n_{h}$ is the hillslope Manning coefficient, $q(t)=\partial Q_{x}(t) / \partial x$ is the outflow rate per unit area, $q_{0}$ is the initial condition (for $t=t_{0}$ ) and $\phi_{S}$ is the shape factor $(S F)$ that depends on both the plan form geometry and the profile shape of the hillslope. $S F$ is given by (Agnese et al., 2007):

$S F=\phi_{S}=\int_{0}^{1}\left[\frac{\phi_{p l}(\xi)}{\sqrt{\phi_{p r}(\xi)}}\right]^{1 / m} d \xi$ where $\phi_{p l}(\xi)$ is called 'normalized plan form geometry function' and $\phi_{p r}(\xi)$ is called the 'normalized profile shape function'. The normalized plan form geometry function is given by (Agnese et al., 2007):

$\phi_{p l}(\xi)=\frac{A(x)}{w(x)} \frac{1}{L}$,

where $A(x)$ and $w(x)$ respectively being the drainage area and the hillslope width at the distance $x$ (Fig. 2). By normalizing the distance $(\xi=x / L)$ and substituting Eq. (2) and Eq. (4) into Eq. (8), we obtain:

$\phi_{p l}(\zeta)=\frac{\int_{0}^{\zeta L} \exp \left[c_{s}(1-\zeta)^{(2-n)}\right] d \zeta}{\exp \left[c_{s}(1-\zeta)^{(2-n)}\right]}$.

Note that in convex/concave hillslopes, the drainage area in each point should be determined numerically and we cannot devise an analytical equation for calculating the plan form function in these hillslopes. In straight hillslopes there is no slope variations $(n=1)$ and the width function is as follows (Talebi et al., 2008a):

$w(x)=w_{0} \exp \left(-\frac{2 \omega L}{H} x\right)$

where $w_{0}$ is the hillslope width at the most upstream $(x=0)$. As a consequence, the hillslope drainage area upstream of $x$ becomes:

$A(x)=\int_{0}^{x} w(x) d u=\frac{w_{0} H}{2 \omega L}\left[1-\exp \left(-\frac{2 \omega L}{H} x\right)\right]$.

The normalized plan form function for the straight hillslopes is calculated by:

$\phi_{p l}(\zeta)=\left(\frac{H}{2 \omega L^{2}}\right)\left[\exp \left(\frac{2 \omega \zeta L^{2}}{H}\right)-1\right]$

The normalized profile shape function is obtained by (Agnese et al., 2007):

$\phi_{p r}(\zeta)=S(x) / S$

where $S(x)$ is the local slope. We can calculate the local slope of compound hillslopes by Eq. (1) as:

$S(x)=\left|\frac{d z}{d x}\right|=n \frac{H}{L}\left(1-\frac{x}{L}\right)^{n-1}=n S(1-\xi)^{n-1}$.

By substituting Eq. (14) into Eq. (13), the normalized profile shape function is obtained:

$\phi_{p r}(\zeta)=n(1-\zeta)^{n-1}$

The normalized profile shape for straight hillslopes $(n=1)$ is equal to unity. By inserting the normalized plan shape function 
from Eq. (9) and the normalized profile shape function from Eq. (15) into Eq. (7), we obtain:

$$
\begin{aligned}
& \phi_{S}=\frac{1}{L} \int_{o}^{L}\left\{\frac{\frac{A(x)}{w(x) L}}{\sqrt{S(x) / S}}\right\}^{1 / m} d x= \\
& \left.=\int_{0}^{1}\left\{\frac{\int_{0}^{\zeta L} \exp \left(c_{s}(1-\zeta)^{(2-n)}\right) d \zeta}{\exp \left(c_{s}(1-\zeta)^{(2-n)}\right)}\right]\right\}^{1 / m} d \zeta .
\end{aligned}
$$

Eq. (16) displays the shape factor function for all complex hillslopes. Also, by inserting the plan shape fuction from Eq. (12) an unify profile shape into Eq. (7), the shape factor for straight hillslopes becomes:

$\phi_{S}=\int_{0}^{1}\left\{\left(\frac{H}{2 \omega L^{2}}\right)\left[\exp \left(\frac{2 \omega \zeta L^{2}}{H}\right)-1\right]\right\}^{1 / m} d \zeta$.

By solving Eq. (16) and Eq. (17) numerically, the shape factor for complex hillslopes can be determined. Eq. (17) has an analytic solution for different values of $m$. For example, the shape factor of parallel-straight hillslope for transition regime $(m=2)$ is $2 / 3$.

\section{Time of concentration for basic complex hillslopes}

We found no consensus in the literature regarding the terms used to describe the time of hillslopes response, or to explain their physical significance. For example, Izzard (1946) defined the time to equilibrium as the time when the flow is $97 \%$ of the supply. Similarly, Machmeier and Larson (1968) used a term called "time to virtual equilibrium", also the time taken to attain $97 \%$ of equilibrium flow. In a broader study, Ben-Zvi (1984) defined the time of concentration as the time from the initiation of rainfall, to the time when the catchment discharge attains (nearly) 0.8 of the equilibrium discharge. Agnese et al. (2007) defined the time to equilibrium as the time necessary for the outflow rate, starting from zero, to attain $95 \%$ to the rainfall excess.

In this paper, the characteristic time-scale of the surface runoff processes is represented by the time of concentration, defined as the time necessary for the outflow rate $q(t)$, starting from zero, to attain a value very close to the rainfall excess $(\chi \cdot r) \cdot \chi$ is called concentration coefficient (CC).

According to Eq. (6), the time of concentration could be expressed by (Agnese et al., 2007):

$$
\begin{aligned}
& T C=R_{S} r^{(1-m) / m}\left(\frac{\sqrt{S}}{n_{h} L}\right)^{-1 / m} \\
& R_{S}=\varphi_{S} \sum_{j=0}^{\infty} \frac{\chi^{(1+m j) / m}}{1+m j}
\end{aligned}
$$

where $R_{s}$ depends on the geometry of hillslopes, flow regime and concentration coefficient. By inserting Eq. (16) into Eq. (18), we obtain:

$$
\begin{aligned}
& T C=\sum_{j=0}^{\infty} \frac{\chi^{(1+m j) / m}}{(1+m j)} r^{(1-m) / m}\left(\frac{\sqrt{S}}{n_{h} L}\right)^{(-1 / m)} \\
& \left.\int_{0}^{1}\left\{\frac{\int_{0}^{\zeta L} \exp \left(c_{s}(1-\zeta)^{(2-n)}\right) d \zeta}{\exp \left(c_{s}(1-\zeta)^{(2-n)}\right)}\right]\right\}^{1 / m} d \zeta \text {. }
\end{aligned}
$$

Eq. (19) computes TC for all nine complex hillslopes in diverse flow regimes. By solving Eq. (19) numerically, TC can be determined.

All parameters of Eq. (19) except the concentration coefficient depend on geometric features of the hillslope and rainfall attributes. This equation shows great sensitivity to concentration coefficient so that partial changes in this coefficient lead to prominent changes in TC. Accordingly, in this work we are to calibrate the concentration coefficient based on the lab results in conjunction with the equations suggested by other scientists.

\section{FURTHER COMPARISONS}

To investigate the effect of geometry of complex hillslopes on TC of surface flow, the nine basic complex hillslopes are further studied in similar conditions that were considered by Hilbert et al. (2004) and Talebi et al. (2008a, b). The geometrical parameters for the nine characterized hillslopes are listed in Table 1. The total length of all hillslopes is $100 \mathrm{~m}$, maximum elevation difference is $26.8 \mathrm{~m}$, average slope is 0.27 , maximum $y$ is $25 \mathrm{~m}$, Manning coefficient assumed 0.03 , and $\mathrm{m}$ set to $5 / 3$ for turbulent flow. The curvature shape factor for hillslopes varies between 0.5 and 1.5 and the plan shape factor between $\omega$ $=-H / L^{2}$ (for divergent) and $\omega=+H / L^{2}$ (for convergent) (Talebi et al., 2008a and Troch et al., 2002). The straight hillslopes have a curvature parameter of unity, while the plan shape factor for parallel hillslopes is zero.

The parameters are so chosen that the characteristics of plan shape in the convergent hillslopes be opposite to those for the divergent ones; also, the curvature aspects of the convex hillslopes are taken to be opposite to the concave ones.

Table 1. Geometrical parameters for nine studied hillslopes (Talebi et al., 2008a, b).

\begin{tabular}{ccccc}
\hline $\begin{array}{c}\text { Hillslope } \\
\text { Nr. }\end{array}$ & $\begin{array}{c}\text { Profile } \\
\text { curvature }\end{array}$ & $\begin{array}{c}\text { Plan } \\
\text { shape }\end{array}$ & $n$ & $\omega\left(10^{-3} \mathrm{~m}^{-1}\right)$ \\
\hline 1 & concave & convergent & 1.5 & +2.7 \\
2 & concave & parallel & 1.5 & 0 \\
3 & concave & divergent & 1.5 & -2.7 \\
4 & straight & convergent & 1 & +2.7 \\
5 & straight & parallel & 1 & 0 \\
6 & straight & divergent & 1 & -2.7 \\
7 & convex & convergent & 0.5 & +2.7 \\
8 & convex & parallel & 0.5 & 0 \\
9 & convex & divergent & 0.5 & -2.7 \\
\hline
\end{tabular}

\section{Calibration of time of concentration equation}

Eq. (19) has a strong dependence on the concentration coefficient, so that small alterations of this quantity greatly affects the time of concentration. Calibration of this coefficient requires measuring the time of concentration of complex 
hillslopes in laboratory. Another way of calibration would be to compare the results of Eq. (19) with those of other scientists. In this research, both calibration and laboratory experiments are used such that the laboratory data forms the ultimate basis for calibration of the proposed relationship.

There exists a close relationship between $T C$, time to equilibrium $\left(T_{e}\right)$ and/or lag time $\left(t_{l}\right)$ of a hillslope or a watershed. $T_{e}$ is the moment at which the runoff peak flow equals the rainfall excess intensity times the watershed area. If the duration of the excess rainfall is greater than or equal to $T C$, then $T_{e}$ is equal to TC. Moreover, $T C$ is $1.67 t_{l}$ (Soil Conservation Service, 1975), 1.49t $t_{l}$ (Overton and Meadows, 1976 and Sharma, 1985), and $1.35 t_{l}$ (McCuen et al., 1984). Singh and Agiralioglu (1981a) proposed $(m+1) t_{l} / m$ which is adopted in this research.

\section{Calibration of TC equation for straight-parallel hillslope}

In this section, Eq. (19) for the parallel-straight hillslope ( $\omega$ $=0, n=1)$ is compared to the relationship proposed by Morgali and Linsley (1965) and Eagleson (1970) to determine the time of concentration of overland flow. Then, we turn to calibrate the concentration time for other types of hillslopes. Morgali and Linsley (1965) and Eagleson (1970) used the following equation to calculate the time of concentration for overland flow over a rectangular plane:

$$
T C=\frac{L^{1 / m}}{\left(\alpha r^{m-1}\right)^{1 / m}},
$$

where $\alpha=\frac{1}{n_{h}} \times S^{0.5}$. If we put $C C=0.832$ and $\mathrm{m}=5 / 3$ in Eq. (18), then $R_{s}=1$. Thus, Eqs. (19) and (20) yield the same results. Fig. 3 illustrates the variations of $R_{s}$ with respect to the parameter $\mathrm{CC}$ for different flow regimes in the straight-parallel hillslopes.

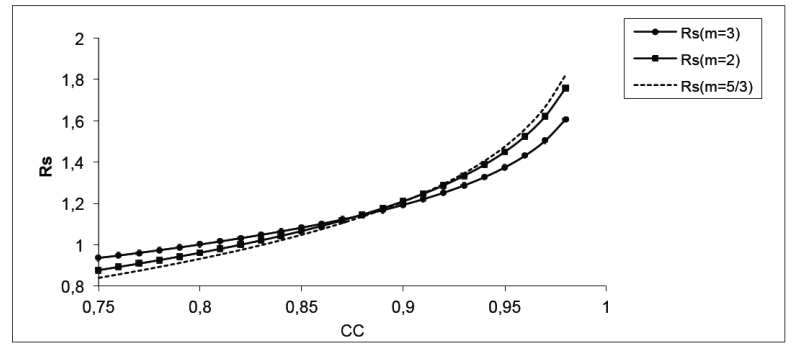

In general, the straight-parallel hillslopes give $R_{S} \propto 1$ at $\mathrm{CC}=$ $=0.832$ for different values of $m$, causing Eq. (19) and Eq. (20) to agree. Therefore, one could set the concentration coefficient of the parallel-straight hillslopes to 0.832 .

\section{Calibration of TC equation for straight-convergent hillslope}

In this section, Eq. (19) for the parallel-convergent hillslopes is linked to the equations presented by Agiralioglu (1985) for convergent surfaces. The lag time for a converging surface can be obtained as Agiralioglu, 1985.

$t_{l}=\left(\frac{1}{L}\right)\left(\frac{1}{2 \alpha}\right)^{1 / m}(r)^{(1-m) / m} \int_{0}^{L}\left[\frac{2 x L-(1-c) x^{2}}{L-(1-c) x}\right]^{1 / m} d x$

where $c$ is the ratio of outlet width to the ridge width (degree of convergence). The approximate relationship between $\mathrm{c}$ and plan shape parameter $(\omega)$ for straight hillslope $(n=1)$ is:

$c=\frac{c_{w}}{w(0)}=\exp \left(-2 \omega L^{2} / H\right)$

TC of a convergent-straight hillslope can be obtained by:

$T C=\frac{m+1}{m} t_{l}$

Fig. 4 shows TC of straight-convergent hillslopes for $m=$ $5 / 3$, various plan shape coefficients $(\omega)$ and concentration coefficients (CC) according to Eq. (23) proposed by Agiralioglu (1985) and Eq. (19) (this study).

Based on Fig. 4, Eqs. (19) and (23) give the best fitted values for $\mathrm{CC}=0.83$. According to the obtained results, the concentration coefficient of the straight-convergent hillslopes equals 0.83 .

In Agiralioglu's (1985) modeling, the hillslope width is a linear function of length (since $w(x)=\theta x$, where $\theta$ is the arch angle), while in our study this relation is exponential (Eq. (2)). Since it is easily understood that the less value of $\omega$, the more the width relation tends to the linear situation; this, in turn, causes that the difference in simulation of flow width in two methods (which is an influencing factor on TC) reduces.

Fig. 3. Effect of concentration coefficient on $R_{s}$ for different flow regimes.

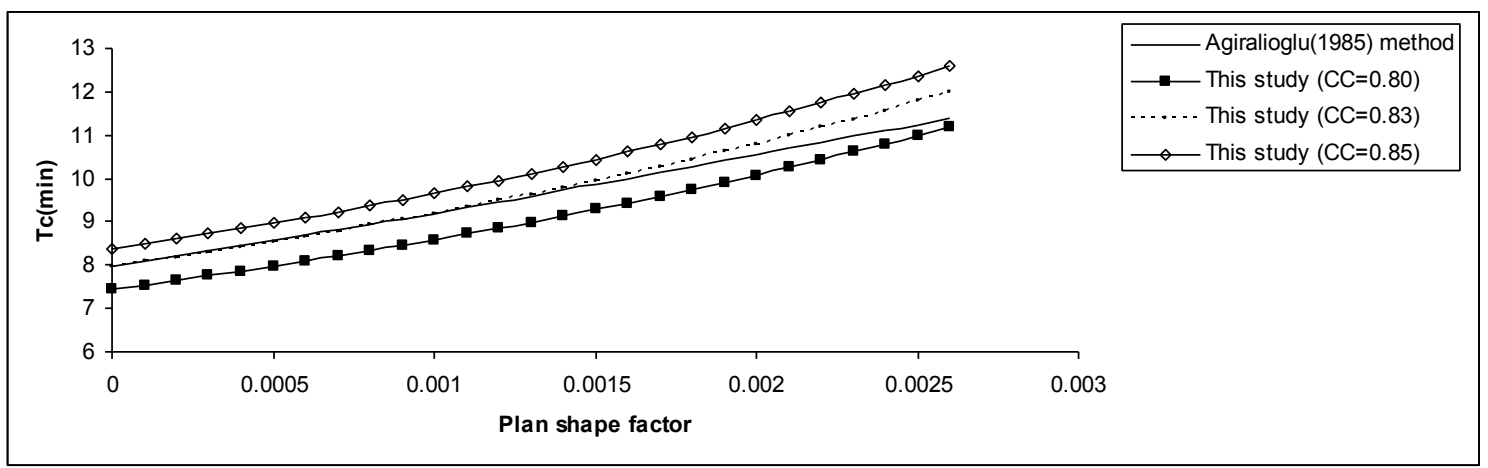

Fig. 4. Comparison of TC determined by Agiralioglu (1985) and this study for the straight-convergent hillslopes. 


\section{Calibration of TC equation for straight-divergent hillslopes}

Agiralioglu and Singh (1981) reported the following equation for lag time of divergent hillslopes:

$t_{l}=\frac{1}{L(1-c)}\left(\frac{r^{1-m}}{2 \alpha}\right)^{1 / m} \int_{c L}^{L}\left[\frac{\left(x^{2}-c^{2} L^{2}\right) d x}{x}\right]^{1 / m}$,

where $c$ is the divergence factor of the hillslope. If the divergence factor is small $(c>0)$, lag time for divergent hillslopes may be obtained by:

$t_{l}=1.147\left(\frac{L^{0.6} n_{h}^{0.6}}{S^{0.3} r^{0.4}}\right)$,

where $r$ is excess rainfall intensity $(\mathrm{cm} / \mathrm{hr})$ and $t_{l}$ is in minute. Since TC is 1.6 times the lag time $(\mathrm{m}=5 / 3)$, then TC for a divergent hillslope becomes:

$T C=0.66\left(\frac{L^{0.6} n_{h}^{0.6}}{S^{0.3} r^{0.4}}\right)$,

where $r$ is the excess rainfall intensity $(\mathrm{m} / \mathrm{s})$ and TC is in seconds.

By putting $m=5 / 3, n=1$ (the straight hillslope), $\omega=-H / L^{2}$ and $\mathrm{CC}=0.83$ in Eq. (19), we get:

$T C=0.73 \frac{L^{0.6} n_{h}^{0.6}}{r^{0.4} S^{0.3}}$

This is close to Eq. (26). Thus, the concentration coefficient for the straight-divergent hillslopes is 0.83 . To calibrate the presented model, Eq. (19) is applied only for straight hillslopes with different plan shapes, setting the concentration coefficient for parallel, divergent and convergent hillslopes to 0.83 .

\section{CALIBRATION OF THE PROPOSED EQUATION BASED ON LABORATORY EXPERIMENTS}

As it was seen before, the equation for TC in this research was compared to those of other scientists only for the case of straight hillslopes with no consideration of curvature effect on concentration coefficient, so we need to use a laboratory model to calibrate the coefficient for the nine complex hillslopes.

Parallel to this work, Geranian et al. (2010) studied the response of surface flow in complex hillslopes through laboratory experiments. They set the length of the hillslopes to $2 \mathrm{~m}$ and the maximum width to $1 \mathrm{~m}$. The upstream width and the down- stream width were $1 \mathrm{~m}$ and $0.2 \mathrm{~m}$ in convergent hillslopes, respectively, while the reserves was true for divergent hillslopes. The profile curvature parameters were 1.5 and 0.5 for concave and convex hillslopes, respectively. The rainfall intensity over the hillslopes varied between 5 to 10 litters per minute. Manning coefficient of hillslopes was 0.016 and bed slopes ranged between $5 \%$ to $20 \%$. The geometrical parameters for the nine hillslopes are listed in Table 2. TC was measured as the time that outlet discharge reached its maximum value at steady state. Fig. (5) shows the rainfall simulator used by Geranian et al. (2010).

Table 2. Geometrical parameters for nine studied hillslopes (Geranian et al., 2010).

\begin{tabular}{ccc}
\hline $\begin{array}{c}\text { Hillslope } \\
\text { Nr. }\end{array}$ & $n$ & $\omega$ \\
\hline 1 & 1.5 & 0.014 \\
2 & 1.5 & 0 \\
3 & 1.5 & -0.014 \\
4 & 1 & 0.018 \\
5 & 1 & 0 \\
6 & 1 & -0.018 \\
7 & 0.5 & 0.014 \\
8 & 0.5 & 0 \\
9 & 0.5 & -0.014 \\
\hline \multicolumn{3}{c}{$L=2 m, S=5 \%$}
\end{tabular}

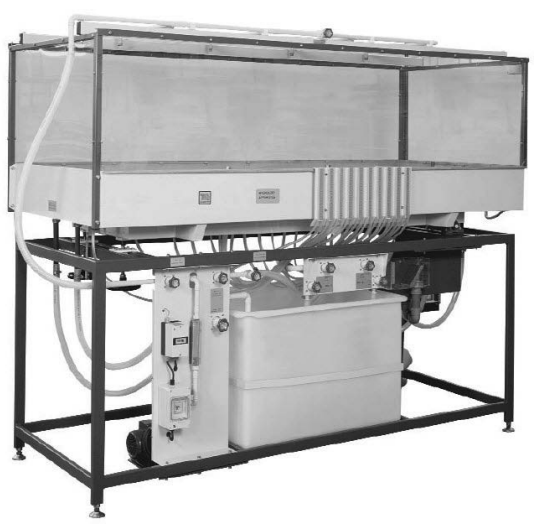

Fig. 5. Rainfall simulator used by Geranian et al. (2010).

Concentration coefficients for concave, straight, and concave hillslopes were calibrated as $0.98,0.94$, and 0.94 , respectively, against the experimental data. Fig. 6 and Table 3 shows the comparison between the TC as determined by the equation proposed in this study with the observed data in the laboratory.

Table. 3. TC observed in lab, and results of Eq. (19) (in seconds)

\begin{tabular}{lccccccccc}
\hline Hillslope Number & 1 & 2 & 3 & 4 & 5 & 6 & 7 & 8 & 9 \\
\hline Obseverd TC & 12.5 & 9.5 & 7.0 & 10.0 & 8.5 & 5.5 & 11.5 & 9.0 & 6.0 \\
Model(CC = 0.83) & 6.7 & 5.2 & 4.1 & 7.1 & 5.3 & 4.4 & 8.2 & 5.9 & 5.0 \\
Model(CC = 0.96) & 10.5 & 8.2 & 6.4 & 11.1 & 8.3 & 6.9 & 12.9 & 9.3 & 7.8 \\
Model(optimized) & 12.3 & 9.6 & 7.5 & 10.0 & 7.5 & 6.2 & 11.6 & 8.3 & 7.0 \\
\hline
\end{tabular}




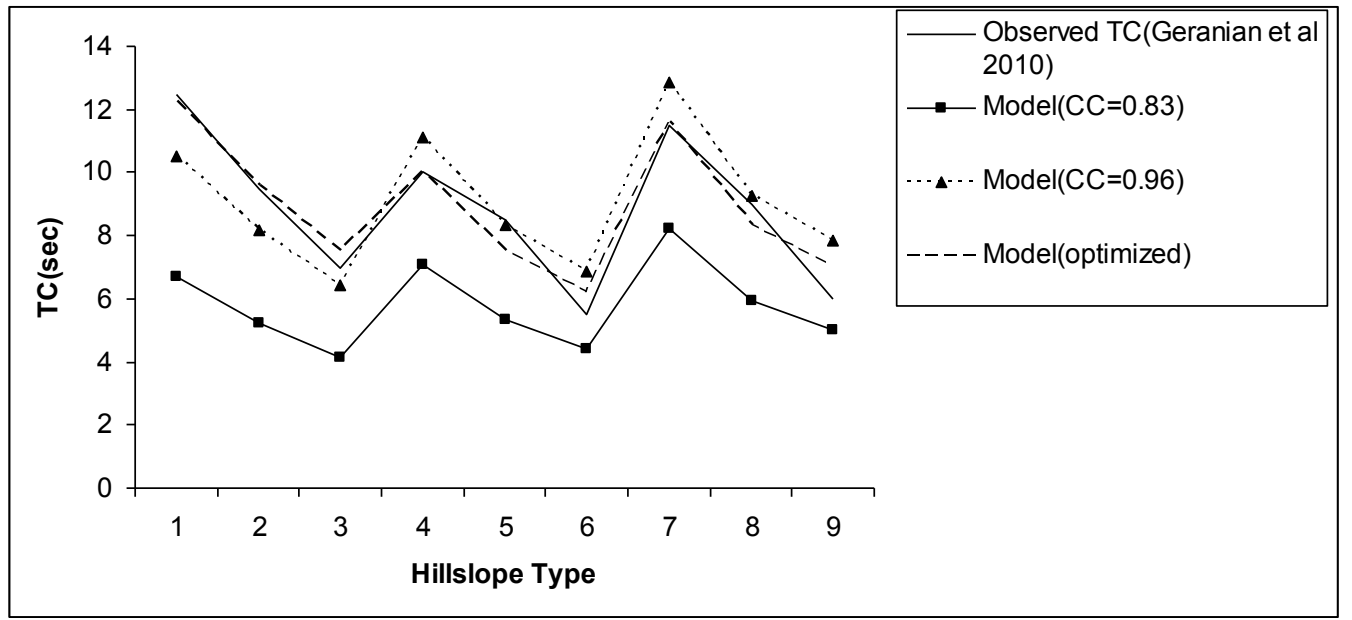

Fig. 6. TC of complex hillslopes with calibrated concentration coefficient (slope $=5 \%$ ).

In average, the concentration coefficient of 0.96 for nine complex hillslopes provided the smallest error for all hillslopes, that is very close to the value of 0.95 proposed by Agnese et al. (2007). Assuming laboratory data to form the benchmark, Eq. (19) is an appropriate relationship to estimate the travel time of complex hillslopes. The data collected by Geranian et al. (2010) indicated that the travel time of convergent hillslopes is approximately twice that of divergent slopes. Furthermore, the travel time of concave hillslopes is slightly more than that of the convex hillslopes. The plan shapes of complex hillslopes were more effective on the surface flow travel time than the profile curvature.

\section{TIME OF CONCENTRATION OF COMPLEX HILLSLOPES}

Considering the fact that the time of concentration is directly related to the shape factor, the variation of TC for complex hillslopes follows the variation of shape factor. Fig. 7) compares TC of complex hillslopes for an excess rainfall intensity of $10 \mathrm{~mm} / \mathrm{hr}$.

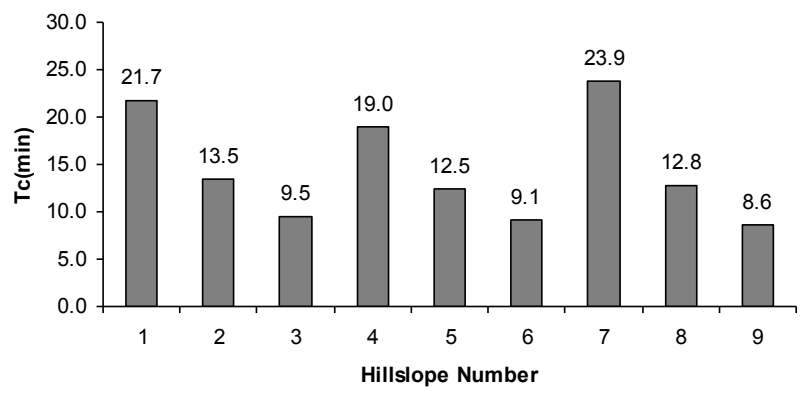

Fig. 7. Time of concentration of complex hillslopes $(r=10$ $\mathrm{mm} / \mathrm{hr}$ ).

Table. 4. Effect of flow regime on TC (in minutes)
Based on the obtained results, divergent hillslopes have smaller TC than those of parallel and convergent slopes. However, convex hillslopes have similar TC to the straight and concave hillslopes. The TC in convergent hillslopes is approximately double those of divergent hillslopes. Smallest TC corresponds to the convex-divergent hillslopes $(8.6 \mathrm{~min})$ and the greatest $\mathrm{TC}$ to the convex-convergent slopes $(23.9 \mathrm{~min})$.

On average, TC for convergent hillslopes is 2.4 and 1.7 times of the divergent and parallel hillslopes, respectively. The effect of convergence coefficient on TC of complex hillslopes was much higher than the effect of curvature coefficient. The $m$ parameter affects time of concentration of the complex hillslopes as shown in Fig. 8 and Table 4 for different flow regimes.

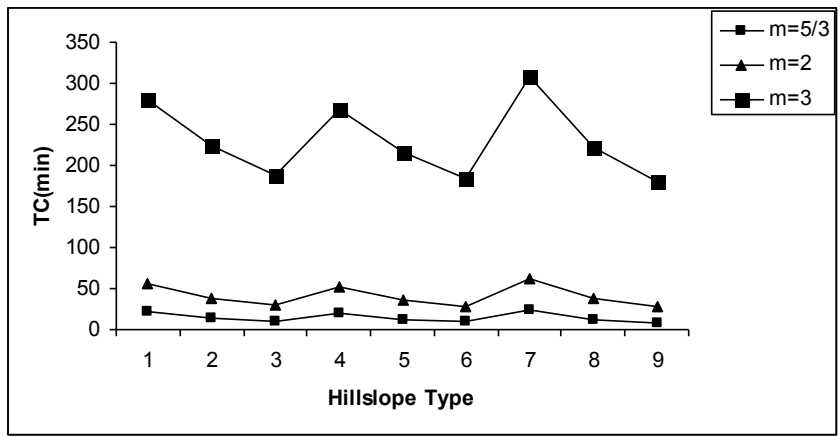

Fig. 8. Effect of surface flow regime on TC for complex hillslopes ( $m=5 / 3$ for turbulent flow, $m=2$ for transition flow and $m=3$ for laminar flow, $r=10 \mathrm{~mm} / \mathrm{hr}$ ).

Flow regime strongly influences TC especially in laminar flow regime. The flow regime in hillslopes is generally turbulent and $m=5 / 3$ is normally adopted.

\begin{tabular}{lcccccccccc}
\hline H.N & 1 & 2 & 3 & 4 & 5 & 6 & 7 & 8 & 9 \\
\hline$m=3$ & 21.7 & 13.5 & 9.5 & 19.0 & 12.5 & 9.1 & 23.9 & 12.8 & 8.6 \\
$m=2$ & 56.7 & 38.9 & 29.5 & 51.7 & 36.7 & 28.5 & 62.7 & 37.8 & 27.3 \\
$m=5 / 3$ & 280.5 & 223.4 & 188.0 & 268.9 & 216.9 & 184.2 & 307.1 & 222.2 & 179.6 \\
\hline
\end{tabular}



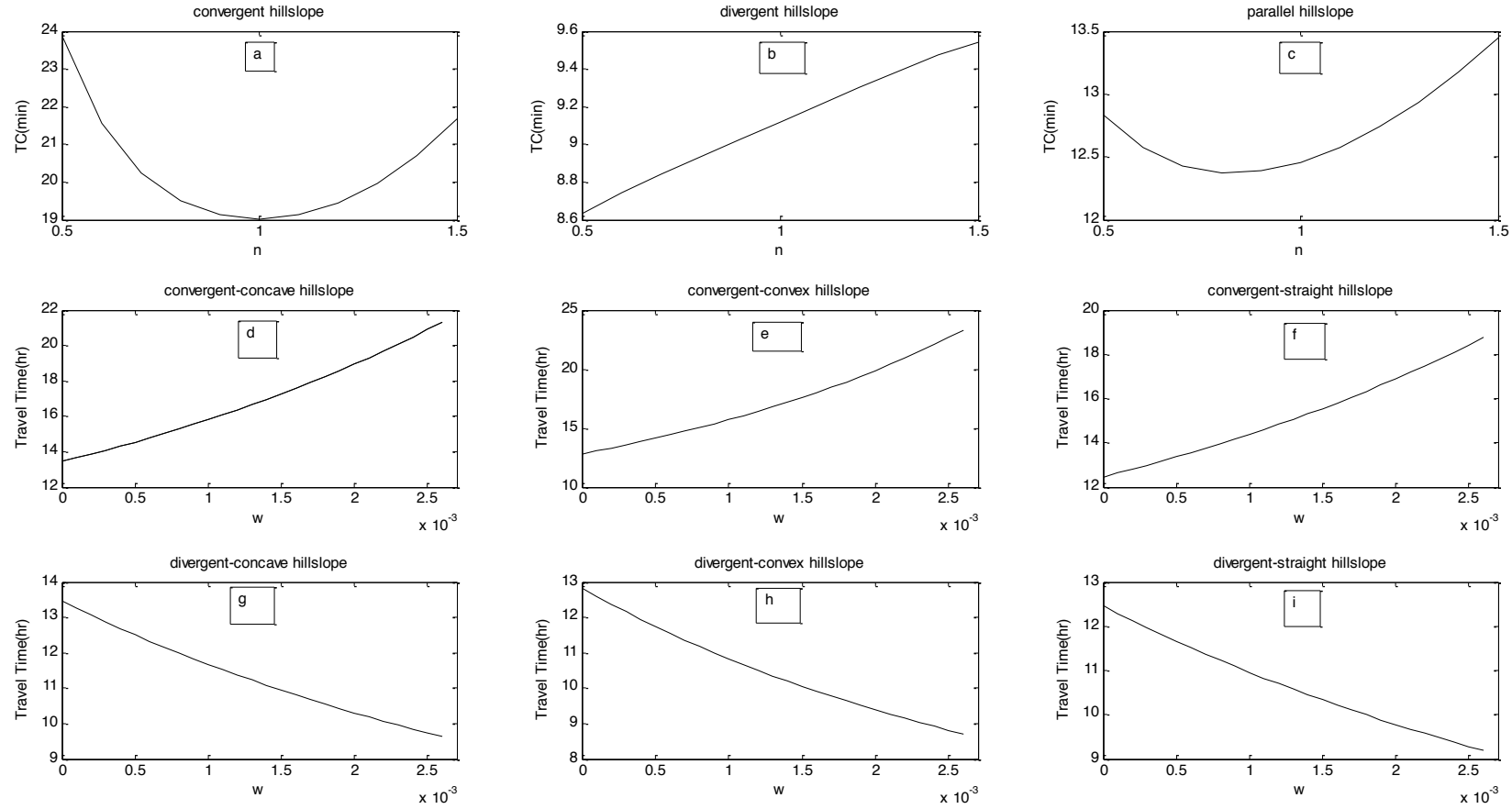

Fig. 9. Effect of profile curvature and plan shape parameters of complex hillslopes on TC ( $r=10 \mathrm{~mm} / \mathrm{hr})$.

\section{The effect of geometry of complex hillslopes on TC}

Now, the effects of geometric parameters of nine hillslopes upon TC are studied. Parameter $n$ in Eq. (1) stands for the profile curvature and $\omega$ (the plan shape) describes convergence or divergence of the hillslope. Fig. $(9 a, b, c)$ shows the influence of the profile curvature of complex hillslopes for different values of $n$ and for different plan shapes according to Table (1) values.

Thus, the effect of profile curvature in parallel and divergent hillslopes is much smaller than that in convergent slopes.

The changes of TC in Fig. 9a were due to the convergence of hillslope rather than curvature. Fig. (9d, e, f, g, h, i) demonstrates the effect of plan shapes $(\omega)$ of convergent and divergent hillslopes on TC. The values of $(\omega)$ is assigned to vary from $-H / L^{2}$ to $+H / L^{2}$. For example, TC of convex-convergent and concave-convergent hillslopes are respectively $25 \%$ and $14 \%$ greater than that of straight-convergent hillslopes. It appears that these six hillslopes react differently to the change of plan shape such that in convergent hillslopes the effect is far more than in divergent slopes.

In divergent hillslopes, the greater the absolute value of $\omega$, the higher the decrease in TC. Changes in profile curvature in divergent hillslopes do not affect TC. Convergent hillslopes are more sensitive compared to divergent and parallel slopes. Also, different profile curvatures exhibit different responses. For example, a convex-convergent hillslope has the maximum TC as compared to convex-straight slopes such that the convergentconvex hillslope $(\omega=0.0027)$ has a TC of 1.86 times that of the parallel-convex slope $(\omega=0)$ and TC for a convergent-concave slope is 1.6 times that of the parallel-concave slope.

Overall, one may state that plan shape factor exert more influence on the TC of surface flow than those the profile curvature. This is particularly bold in convergent hillslopes than divergent ones.

\section{CONCLUSIONS}

In this article, a general relationship was presented for computing the TC of complex hillslopes considering the plan shape and profile curvature. The $3 \mathrm{D}$ geometry of complex hillslopes was formalized and the parameters defining plan shape and profile curvature were incorporated into the TC relationship. The results obtained for straight hillslopes with convergent, parallel and divergent shapes were shown to agree with those reported by Singh and Agiralioglu (1981a, 1981b, 1982) and Agiralioglu (1985). Finally, the proposed relationship was calibrated against the laboratory data. Main conclusions of this study are as follows:

1. Experimentally calibrated concentration coefficients for concave, straight, and convex hillslopes are 0.98, 0.94, and 0.94 , respectively.

2. Based on the laboratory evidence, the TC of complex hillslopes was regarded as the time when the flow reaches 0.96 of excess rainfall intensity.

3. Convergent hillslopes with different profile curvatures have longer TC as compared to the parallel and divergent slopes. For example, average TC for convergent hillslopes is about 2.4 times those of divergent hillslopes and 1.7-times those of parallel slopes under similar conditions.

4. The plan shape of hillslopes greatly influences the TC. In contrast, the profile curvatures has a slight effect. The effect of profile curvatures on converging hillslopes is higher than that on divergent or parallel slopes. TC of convex hillslopes with constant plan shape is close to TC for straight and concave hillslopes.

5. TC for convergent hillslopes is almost twice that for parallel and divergent slopes. Convergent-convex hillslopes are dominate hillslopes in comparison to other types in nature. TC of convergent - convex hillslopes is 1.25 times those of straightconvergent and 2-times those of parallel-straight hillslopes. 


\section{REFERENCES}

Agiralioglu, N., 1985. A comparison of water lag times for converging and plane surfaces. Nordic Hydrology, 16, 169176.

Agiralioglu, N., 1988. Estimation of the time of concentration for diverging surface. J. Hydrol. Sci, 33(2), 173-179.

Agiralioglu, N., Singh, V.P., 1981. Kinematic wave monograph for time of concentration and lag time. Irrigation and Power Journal, 38(4), 351-358.

Agnese, C., Baiamonte, G., Corrao, C., 2001. A simple model of hillslope response for rainfall-excess mechanism of runoff generation. Hydrological Processes, 15, 3225-3238.

Agnese, C., Baiamonte, G., Corrao, C., 2007. Overland flow generation on hillslopes of complex topography: analytical solutions. Hydrol. Process., 21, 1308-1317.

Akan, A.O., 1986. Time of concentration of overland flow. J. Irrig. Drain. Eng. Asce, 112(4), 283-292.

Aryal, S.K., O’Loughlin, E.M., Mein, R.G., 2005. A similarity approach to determine response times to steady-state saturation in landscapes. Advances in Water Resources, 28, 99 115.

Ben-Zvi, A., 1984. Runoff peaks from two dimensional laboratory watersheds. J. Hydrol., 68, 115-139.

Ben-Zvi, A., 1995. The influence of storm temporal patterns on catchment response - Comment. J. Hydrol., 172, 379-380.

Berne, A., Uijlenhoet, R., Troch, P.A., 2005. Similarity analysis of subsurface flow response of hillslopes with complex geometry. Water Resour. Res., 41, W09410, doi: 10.1029/2004WR003629.

Beven, K., 1982. On subsurface stormflow: an analysis of response times. Hydrol. Sci J., 27(4), 505-521.

Eegleson, P.S., 1962. Unit hydrograph characteristics for sewered areas. Journal of the hydraulics division. Proceedings of the American Society of the Civil Engineers, 88(Hy2), 1-25.

Eagleson, P.S., 1970. Dynamic Hydrology. McGraw-Hill, New York, USA.

Evans, I.S., 1980. An integrated system of terrain analysis and slope mapping. Zeitschrift fur Geomorphologie, Supplementband, 36, 274-295.

Geranian, M., Amanian, N., Talebi, A., 2010. Optimization of the topography effects on time of pounding. MSc thesis, (abstract in English), Yazd University, Iran.

Henderson, F.M., Wooding, R.A. 1964. Overland flow and groundwater flow from a steady rain of finite duration. Journal of Geophysical Research, 69(8), 1531-1540.

Hilberts, A., Van Loon, E., Troch, P.A., Paniconi, C., 2004. The hillslope-storage Boussinesq model for non-constant bedrock slope. J. Hydrol., 291, 160-173.

Hilberts, A., Troch, P.A., Paniconi, C., Boll, J., 2007. Lowdimensional modeling of hillslope subsurface flow: the relationship between rainfall, recharge, and unsaturated storage. Water Resour. Res., 43 W03445, doi: 10.1029/ 2006WR006496.

Horton, R.E., 1938. The interpretation and application of runoff plane experiments with reference to soil erosion problems. Soil Science Society of America Proceedings, 1, 401-437.

Izzard, C.F., 1946. Hydraulics of runoff from developed surfaces. Proc. High Res. Board, 26, 129-150.

Kirpich, T.P., 1940. Time of concentration of small agricultural watersheds. Civil Engineering, 10(6), 362.
Machmeier, R.E., Larson, C.L., 1968. Runoff hydrographs for mathematical watershed model. J Hydraul. Div. ASCE, 94(6), 1453-1474.

McCuen, R.H., Wong, S.L., Rawls, W.J., 1984. Estimating urban time of concentration. Journal of Hydraulic Engineering, 110(7), 887-904.

Meynink, W.J.C., 1978. Catchment time response. Darling Downs Institute of Advance Education, Australia, project 44/1977, pp. 32.

Morgali, J.R., Linsley, R.K., 1965. Computer simulation of overland flow. Journal of the Hydraulics Division, ASCE, 90(HY30), 81-100.

O'Loughlin, E.M., 1981. Saturation regions in catchments and their relations to soil and topographic properties. J. Hydrol., 53, 229-246.

Overton, D.E., Meadows, M.E., 1976. Storm Water Modeling. Academic Press, New York.

Sabzevari, T., 2010. Development of catchments geomorphological instantaneous unit hydrograph based on surface and subsurface flow response of complex hillslopes. Phd thesis (abstract in English), Department of Civil Engineering, Science and Research Branch, Islamic Azad University, Tehran, Iran.

Sabzevari, T., Talebi, A., Ardakanian, R., Shamsai, A., 2010. A steady-state saturation model to determine the subsurface travel time (STT) in complex hillslopes. Hydrol. Earth Syst. Sci., 14, 891-900.

Saghafian, B., Julien, P.Y., 1995. Time to equilibrium for spatially variable watersheds. J. Hydrol. 172, 231-245.

Sharma, T.C., 1985. Stochastic models applied to evaluating hydrologie changes. J. Hydrol., 78, 61-81.

Singh, V.P., Agiralioglu, N., 1981a. Diverging overland flow. 1. Analytical solutions, Nordic Hydrology, 12(2), 81-89.

Singh, V.P., Agiralioglu, N., 1981b. Diverging overland flow. 2. Application to natural watersheds. Nordic Hydrology, 12(2), 99-110.

Singh, V.P., Agiralioglu, N., 1982. Lag time for diverging overland flow. Nordic Hydrology, 13, 39-48.

Soil Conservation Service, 1975. Urban hydrology for small watersheds. Technical Release No. 55. Chester, P.A., U.S. Department of Agriculture, Soil Conservation Service, $91 \mathrm{pp}$.

Talebi, A., Troch, P.A., Uijlenhoet, R., 2008a. A steady-state analytical hillslope stability model for complex hillslopes. Hydrol. Process., 22, 546-553.

Talebi, A., Uijlenhoet, R., Troch, P.A., 2008b. A lowdimensional physically-based model of hydrologic control of shallow landsliding on complex hillslopes. Earth Surf Process Landforms, 33(13), 1964-1976.

Troch, P.A., Paniconi, C., Van Loon, E., 2003. Hillslopestorage Boussinesq model for subsurface flow and variable source areas along complex hillslopes. 1-Formulation and characteristic response. Water Resour. Res., 39(11), 1316.

Troch, P.A., Van Loon, A.H., Hilberts, A.G.J., 2002. Analytical solutions to a hillslope storage kinematic wave equation for subsurface flow. Adv. Water Resour., 25(6), 637-649.

Received 21 June 2011 Accepted 3 February 2013 